\title{
Trait Mindfulness and Wellness in Multiple Sclerosis
}

\author{
Ola Mioduszewski, Heather MacLean, Patricia A. Poulin, Andra M. Smith, \\ Lisa A. S. Walker
}

\begin{abstract}
Multiple sclerosis (MS) is a chronic, progressive, autoimmune, neurodegenerative disorder that can interfere with physical and psychological functioning, negatively affecting health-related quality of life (HRQoL). Fostering mindfulness may mitigate the negative consequences of MS on HRQoL. The relationship between mindfulness, mood and MS-related quality of life was investigated. In total, 52 individuals with MS completed questionnaires to examine the relationship between trait mindfulness and wellness. Higher levels of trait mindfulness were associated with better HRQoL, lower depression and anxiety, lower fatigue impact and fewer perceived cognitive deficits. Mindfulness interventions have the potential to enhance wellness in those living with MS.
\end{abstract}

RÉSUMÉ: États de pleine conscience et de bien-être chez des patients atteints de sclérose en plaques. La sclérose en plaques (SP) est une maladie chronique, évolutive, auto-immune et neuro-dégénérative qui peut perturber le fonctionnement physique et psychologique d'une personne, affectant ainsi négativement sa qualité de vie liée à la santé (QVLS). À cet égard, il est possible que le fait de favoriser chez des patients un état de pleine conscience (mindfulness) puisse atténuer les conséquences négatives de la SP sur la QVLS. Le lien entre un état de pleine conscience, l'humeur et la qualité de vie de ceux et celles atteints de la SP a été étudié. Ainsi, cinquante-deux individus aux prises avec la SP ont répondu à des questionnaires afin qu'on puisse analyser la relation existant entre les aspects se rapportant à un état de pleine conscience et le bien-être. Des niveaux plus élevés d'état de pleine conscience ont ainsi été associés à une meilleure QVLS, à des niveaux moins élevés de dépression et d'anxiété, à un impact moins important de la fatigue et à un nombre moins important de déficits cognitifs tels que perçus par les patients. En somme, des interventions focalisant sur un état de pleine conscience ont le potentiel d'améliorer le bien-être des personnes vivant avec la SP.

Keywords: Mindfulness, Multiple sclerosis, Quality of life, Cognition, Mood

doi:10.1017/cjn.2018.51

Can J Neurol Sci. 2018; 45: 580-582

Health-related quality of life (HRQoL) is the extent to which an individual is subjectively satisfied with life and the experience of pleasure despite the presence of disease. ${ }^{1}$ Persons living with multiple sclerosis (PLWMS) report lower HRQoL compared with the general population. This is because of physical impairment, cognitive impairment, mood dysfunction, pain, fatigue, sexual dysfunction, spasticity, elimination problems and sleep difficulties. $^{2}$ Multiple sclerosis (MS) can also negatively affect professional and social life through loss of employment and decreased participation in recreational activities. Therefore, finding easy-to-implement and effective interventions for symptom management that are acceptable to PLWMS is important given its severe, burdensome and unpredictable nature. This paper includes only a selective sampling of the literature in this rapidly growing area of research.

A characteristic that may assist people in maintaining higher HRQoL is trait mindfulness - the innate (but potentially modifiable) ability to pay attention, on purpose, in the present moment, non-judgementally. Trait mindfulness is negatively associated with psychological distress, rumination and social anxiety ${ }^{3}$ and is reported to moderate the relationship between pain and depressive symptoms. ${ }^{4}$ The objective of this cross-sectional exploratative study was to determine whether trait mindfulness is related to HRQoL and other wellness variables in PLWMS. It was hypothesized that levels of mindfulness would positively correlate with HRQoL and inversely relate to depression, anxiety, fatigue, subjective cognitive dysfunction and pain.

The study was approved by the Ottawa Health Science Network Research Ethics Board (Protocol \#20140197-01H) and participants were recruited from The Ottawa Hospital MS Clinic. To be eligible, patients had to (1) be between 18 and 65 years of age, (2) have clinically definite multiple sclerosis (McDonald criteria), (3) be fluent in English and (4) agree to be contacted for research. Patients who had consented to participate were initially contacted by phone and were subsequently sent a link to the online survey by email once appropriate informed consent was received.

The following demographic and medical characteristics were collected: age, gender, type of MS and most recent Expanded Disability Status Scale (EDSS) score. In addition, participants completed the following questionnaires: The Multiple Sclerosis Quality of Life Inventory (MSQLI), composed of

From the School of Psychology, The University of Ottawa, Ottawa, Ontario, Canada (OM, PAP, AMS, LASW); Department of Medicine, The Ottawa Hospital, Ottawa, Ontario, Canada (HM, PAP, LASW); The Ottawa Hospital Research Institute, Ottawa, Ontario, Canada (HM, PAP, AMS, LASW); University of Ottawa Brain and Mind Research Institute, Ottawa, Ontario, Canada (HM, PAP, AMS, LASW)

Received November 29, 2017. Revised March 13, 2018. Final Revisions SubmitTED MARCH 31, 2018.

Correspondence to: Lisa A. S. Walker, The Ottawa Hospital, 501 Smyth Road, Suite 7300, Ottawa, ON, Canada K1H 8L6. Email: lwalker@toh.ca 
Table 1: Mindfulness correlations with quality of life as measured by the Multiple Sclerosis Quality of Life Inventory (MSQLI)

\begin{tabular}{l|l|l|l|l}
\hline $\begin{array}{l}\text { Five-Factor } \\
\text { Mindfulness } \\
\text { Questionnaire }\end{array}$ & $\begin{array}{c}\text { MSQLI } \\
\text { vitality }\end{array}$ & $\begin{array}{c}\text { MSQLI } \\
\text { social } \\
\text { function }\end{array}$ & $\begin{array}{c}\text { MSQLI } \\
\text { role- } \\
\text { emotional }\end{array}$ & $\begin{array}{c}\text { MSQLI } \\
\text { mental } \\
\text { health }\end{array}$ \\
\hline Observe & $r=0.014$ & $r=-0.024$ & $r=0.065$ & $r=0.235$ \\
\hline Describe & $p=0.920$ & $p=0.865$ & $p=0.649$ & $p=0.093$ \\
\hline Act with awareness & $r=0.155$ & $r=0.148$ & $r=0.381$ & $r=0.275$ \\
\hline Non-judgement & $r=0.310$ & $r=0.222$ & $r=0.347$ & $r=0.304$ \\
\hline & $p=0.272$ & $p=0.295$ & $p=0.005^{* *}$ & $p=0.049^{*}$ \\
\hline Non-reactivity & $r=-0.017$ & $r=0.211$ & $r=0.394$ & $r=0.383$ \\
\hline & $p=0.907$ & $p=0.411$ & $p=0.030^{*}$ & $p=0.012^{*}$ \\
\hline Total score & $r=0.147$ & $r=0.219$ & $r=0.454$ & $r=0.469$ \\
\hline & $p=0.303$ & $p=0.123$ & $p=0.001^{* *}$ & $p<0.001^{* * *}$ \\
\hline
\end{tabular}

$* p<0.05 ; * * p<0.01 ; * * * p<0.001$.

10 well-established psychometrically sound scales measuring fatigue, pain effects and self-perceived cognitive deficits; The Patient Health Questionnaire-9 (PHQ-9), a validated nine-item scale evaluating the severity of depressive symptoms; The Generalized Anxiety Disorder-7 (GAD-7), a seven-item questionnaire evaluating anxiety; and the Five Facet Mindfulness Questionnaire (FFMQ), evaluating the five theoretical subfacets of mindfulness-non-reactivity to inner experience, observing, describing, acting with awareness and non-judging of experience.

Pearson's two-tailed bivariate correlations were used to evaluate the relationship between mindfulness and the other factors indicated (HRQoL, mood and so on). In addition, an adjusted linear regression model was used to further explore the relationship among the five facets of mindfulness and their predictive strength on variables of interest. All analyses were completed using SPSS version 20; significance was set at $p<0.05$. To achieve sufficient statistical power, a minimum sample size of 44 (level of significance $=0.05$, effect size $=0.54$ and power $=0.8$ ) was required. $^{5}$

A total of 156 patients were approached. All 84 PLWMS who met inclusion criteria consented to participate; 52 PLWMS (39 women and 13 men; mean age 47.00 [10.51] years, ranging from 26 to 67; mean EDSS 2.41 [2.15], ranging from 0 to 8) completed the questionnaires. There were 36 participants with relapsing-remitting MS, 10 with secondary-progressive, 4 with primary-progressive, 1 with clinically isolated syndrome and for 1 participant the diagnosis was not available.

Results revealed that some facets of trait mindfulness (i.e. describe, act with awareness, non-judgement, non-reactivity) were positively correlated with the mental health and role-emotional aspects of HRQoL (Table 1). Act with awareness, non-judgement, and non-reactivity were negatively correlated with depression and anxiety, with describe also being negatively correlated with depression (Table 2). Table 2 also demonstrates that various facets of trait mindfulness are negatively correlated with fatigue, perceived cognitive deficits and, to a lesser degree, pain experience. Notably, perceived cognitive deficits demonstrated the strongest negative correlation $(r=-0.57, p<0.0001)$ with the FFMQ total score. Last, significant regression models emerged for all variables of interest, suggesting that all components of trait mindfulness together can predict mood, fatigue, pain experience and perceived cognitive deficits (Table 3). Regression models for depression and anxiety did not reveal specific predictor variables, suggesting that there is a significant degree of collinearity between the various components of mindfulness practice (i.e. one's ability to observe one's experience is closely related to one's ability to describe that experience).

"Mindfulness" is conceptualized as effectively reflecting on the present moment in an open and intentional manner. It is a practice that is achieved through observing the breath, body scanning, meditation, attention shifting and mindful movement.

Table 2: Mindfulness correlations with mood, pain, fatigue and perceived cognition

\begin{tabular}{|c|c|c|c|c|c|}
\hline Five-Factor Mindfulness Questionnaire & Depression (PHQ-9) & Anxiety (GAD-7) & Pain (PES) & Fatigue (mFIS) & Cognition (PDQ) \\
\hline \multirow[t]{2}{*}{ Observe } & $r=-0.111$ & $r=-0.140$ & $r=0.153$ & $r=0.077$ & $r=-0.159$ \\
\hline & $p=0.433$ & $p=0.328$ & $p=0.280$ & $p=0.598$ & $p=0.274$ \\
\hline \multirow[t]{2}{*}{ Describe } & $r=-0.511$ & $r=-0.273$ & $r=-0.124$ & $r=-0.338$ & $r=-0.429$ \\
\hline & $p=0.000 * * *$ & $p=0.055$ & $p=0.386$ & $p=0.019^{*}$ & $p=0.002 * *$ \\
\hline \multirow[t]{2}{*}{ Act with awareness } & $r=-0.421$ & $r=-0.346$ & $r=-0.265$ & $r=-0.505$ & $r=-0.709$ \\
\hline & $p=0.002 * *$ & $p=0.013^{*}$ & $p=0.058$ & $p=0.000 * * *$ & $p=0.000^{* * *}$ \\
\hline \multirow[t]{2}{*}{ Non-judgement } & $r=-0.358$ & $r=-0.396$ & $r=-0.202$ & $r=-0.309$ & $r=-0.183$ \\
\hline & $p=0.009 * *$ & $p=0.004^{*} *$ & $p=0.150$ & $p=0.031^{*}$ & $p=0.209$ \\
\hline \multirow[t]{2}{*}{ Non-reactivity } & $r=-0.327$ & $r=-0.337$ & $r=-0.320$ & $r=-0.281$ & $r=-0.335$ \\
\hline & $p=0.018^{*}$ & $p=0.016^{*}$ & $p=0.021 *$ & $p=0.050^{*}$ & $p=0.018^{*}$ \\
\hline \multirow[t]{2}{*}{ Total score } & $r=-0.530$ & $r=-0.489$ & $r=0.210$ & $r=-0.427$ & $r=-0.566$ \\
\hline & $p=0.000 * * *$ & $p=0.000 * * *$ & $p=0.138$ & $p<0.002 * *$ & $p=0.000^{* *}$ \\
\hline
\end{tabular}

GAD-7 = Generalized Anxiety Disorder-7; mFIS = Modified Fatigue Impact Scale; PDQ = Perceived Deficits Questionnaire; PES = Pain Effects Scale; PHQ-9 = The Patient Health Questionnaire-9.

$* p<0.05 ; * * p<0.01 ; * * * p<0.001$. 


\section{Table 3: Exploratory analysis}

\begin{tabular}{l|l|l|l|l}
\hline $\begin{array}{l}\text { Variable of } \\
\text { interest }\end{array}$ & $\boldsymbol{F}$ & $\boldsymbol{p}$ & Adjusted $\boldsymbol{R}^{\mathbf{2}}$ & $\begin{array}{l}\text { Significant } \\
\text { predictor FFMQ } \\
\text { variables }\end{array}$ \\
\hline Depression & $F=6.155$ & $p<0.0001^{* * *}$ & $R_{\text {adj }}^{2}=0.340$ & $\mathrm{n} / \mathrm{a}$ \\
\hline Anxiety & $F=30.596$ & $p=0.008^{* *}$ & $R_{\text {adj }}^{2}=0.209$ & $\mathrm{n} / \mathrm{a}$ \\
\hline Fatigue & $F=5.275$ & $p=0.001^{* *}$ & $R_{\text {adj }}^{2}=0.313$ & Observe \\
\hline Pain & $F=2.919$ & $p=0.023^{*}$ & $R_{\text {adj }}^{2}=0.161$ & Observe \\
\hline $\begin{array}{c}\text { Perceived } \\
\text { cognitive } \\
\text { deficits }\end{array}$ & $F=9.849$ & $p<0.0001^{* * *}$ & $R_{\text {adj }}^{2}=0.485$ & $\begin{array}{l}\text { Describe } \\
\text { awareness }\end{array}$ \\
\hline
\end{tabular}

FFMQ $=$ Five Facet Mindfulness Questionnaire.

$* p<0.05 ; * * p<0.01 ; * * * p<0.0001$.

These and other practices are the core meditation practices in mindfulness-based stress reduction and mindfulness-based cognitive therapy. Classified as a holistic treatment, mindfulnessbased interventions (MBI) are now frequently used for several disorders such as anxiety, depression, skin diseases, pain, immune disorders, hypertension and diabetes. ${ }^{4}$ Potential benefits of the practice include improved sustained attention, emotional regulation, self-awareness and openness to experience. Trait mindfulness, a person's characteristic or baseline level of mindfulness, affects interpersonal behavior by promoting self-expression and lowering anxiety in social situations, as well as increasing empathy. ${ }^{6}$

The results from our analysis demonstrated that PLWMS with higher levels of trait mindfulness experience better psychological health and better HRQoL. On the administered measures, those who are more mindful are less likely to report symptoms of depression and anxiety, are less likely to report fatigue, report less pain experience and are less likely to report cognitive dysfunction. When maintaining a mindful orientation, attention is directed to the present moment, thus allowing the individual to refrain from ruminating over past events, or continuously thinking about the future. Despite the limitations associated with this study including the non-experimental design and the small sample size, the results echo others where mindfulness is implicated as an important protective factor against depression, ${ }^{4}$ pain interference, ${ }^{7}$ fatigue,${ }^{5}$ as well as emotional distress and trait anxiety. ${ }^{8}$

Given the association between trait mindfulness and wellnessrelated variables in MS, there is a need for further interventional research to determine whether trait mindfulness can be enhanced in this population, thereby potentially having a positive impact on HRQoL. Mindfulness-based interventions have been incorporated into complimentary alternative medical treatment programs for PLWMS and are now recommended in the NICE guidelines for MS. After completing a course in Mindfulness Based Stress Reduction, PLWMS experience increased QoL, fewer depressive symptoms and less fatigue. ${ }^{9}$

Current data document clear associations among mindfulness sub-facets and factors affecting HRQoL. Specifically, the ability to act with awareness, maintenance of an open and non-judgemental perspective and the ability to describe experience demonstrate potential for influencing HRQoL, mood, perceived cognitive deficits and fatigue. In addition, research on the potential for MBI to influence objective cognition in PLWMS is also needed given that this area has demonstrated promise in other populations and has not been currently explored within the MS literature.

Those with high trait mindfulness are able to demonstrate attention, awareness and acceptance of present moment situations, outcomes, sensations and feelings-skills that some identify as essential ingredients contributing to psychological well-being. ${ }^{10}$ Incorporating mindfulness into the continuum of MS care may thus prove useful in providing patients with effective skills to assist in ameliorating debilitating symptoms (e.g. mood dysfunction, fatigue, perceived cognitive impairment, subjective pain).

\section{ACKNOWLEDGMents}

The authors would to thank the participants for their time and for their dedication to MS research.

\section{STATEMENT OF AUTHORSHIP}

OM: participant recruitment, data management, analyses, and manuscript preparation. HM: project conception, participant recruitment, and manuscript editing. PAP: project conception, statistical support, and manuscript editing. AMS: project conception and manuscript editing. LASW: project conception, participant recruitment, data management, analyses, manuscript preparation, and manuscript editing.

\section{Disclosures}

The authors have nothing to disclose.

\section{REFERENCES}

1. Benedict RHB, Wahlig E, Bakshi R, et al. Predicting quality of life in multiple sclerosis: accounting for physical disability, fatigue, cognition, mood disorder, personality, and behavior change. J Neurol Sci. 2005;231(1):29-34.

2. Kargiotis O, Paschali A, Messinis L, Papathanasopoulos P. Quality of life in multiple sclerosis: effects of current treatment options. Int Rev Psychiatry. 2010;22(1):67-82.

3. Carmody J, Baer RB. Relationships between mindfulness practice and levels of mindfulness, medical and psychological symptoms and well-being in a mindfulness-based stress reduction program. J Behav Med. 2008;31(1):23-33.

4. Poulin PA, Romanow HC, Rahbari N, et al. The relationship between mindfulness, pain intensity, pain catastrophizing, depression, and quality of life among cancer survivors living with chronic neuropathic pain. Support Care Cancer. 2016;24:4167-75.

5. Grossman P, Kappos L, Gensicke H, D’Souza M, Mohr DC, Penner IK. MS quality of life, depression, and fatigue improve after mindfulness training: a randomized trial. Neurology. 2010;75 (13):1141-9.

6. Dekeyser M, Raes F, Leijssen M, Leysen S, Dewulf D. Mindfulness skills and interpersonal behaviour. Pers Individ Dif. 2008;44 (5):1235-45.

7. Senders A, Borgatti A, Hanes D, Shinto L. Association between pain and mindfulness in multiple sclerosis: a cross-sectional survey. Int J MS Care. 2018;20:28-34.

8. Crescentini C, Matiz A, Cimenti M, Pascoli E, Eleopra R, Fabbro F. The effect of mindfulness meditation on personality and psychological well-being in patients with multiple sclerosis. Int J MS Care. 2017. https://doi.org/10.7224/1537-2073.2016-093.

9. Blankspoor RJ, Schellekens MPJ, Vos SH, Speckens AEM, de Jong BA. The effectiveness of mindfulness-based stress reduction on psychological distress and cognitive functioning in patients with multiple sclerosis: a pilot study. Mindfulness. 2017;8(5):1251-8.

10. Bogosian A, Hughes A, Norton S, Silber E, Moss-Morris R. Potential treatment mechanisms in mindfulness-based intervention for people with progressive multiple sclerosis. Br J Health Psychol. 2016;21(4):859-80. 